\title{
Pesquisa visual e Ideação na prática projetual: um estudo de caso da plataforma Inspaedia
}

\author{
Visual research and Ideation in the projectual practice: \\ a case study of the Inspaedia platform
}

VIARO, Felipe; Mestre; Universidade Federal do Rio Grande do Sul

felipe_viaro@hotmail.com

HALPERN, Marcelo; Mestre; Universidade Federal do Rio Grande do Sul

marcelohalpern@gmail.com

SILVA, Tânia Koltermann; Doutora; Universidade Federal do Rio Grande do Sul

tania.koltermann@ufrgs.br

SILVA, Régio Pierre da; Doutor; Universidade Federal do Rio Grande do Sul

regio@ufrgs.br

\section{Resumo}

A aplicação do repertório visual a novos contextos projetuais é um fator crítico para a criatividade e geração de novas ideias de estudantes e profissionais do design. Embora atualmente existam ferramentas de pesquisa visual capazes de gerar resultados quantitativamente expressivos, torna-se complexo estabelecer conexões significativas entre estes resultados. Nesse contexto, o Inspaedia apresenta-se como uma ferramenta de pesquisa visual colaborativa que permite estabelecer tais conexões através de um sistema de indexação por tags, curadoria de conteúdo e visualização de informações. Portanto, o objetivo deste trabalho é explorar a ferramenta Inspaedia como um recurso de inspiração criativa e ensino projetual através de um estudo de caso de herança genética visual. Os resultados obtidos demonstram duplo benefício, através do potencial para a criatividade na fase de ideação obtido com pesquisas de qualidade, bem como, o potencial para o ensino do design através da visualização da herança genética visual de peças gráficas.

Palavras Chave: repertório; ideação; criatividade.

\section{Abstract}

The application of the visual repertoire and new contexts is a critical factor for creating and generating new ideas for students and design professionals. Although there are visual search tools capable of generating quantitatively expressive results, it becomes a dynamic resource for connections between results. In this context, Inspaedia presents itself as a collaborative visual search tool that allows the identification of variables through a system of indexing by tags, content curation and information visualization. Therefore, the work is explored as a resource of inspiration and teaching through a case study of a visual genetic inheritance. The result was a double benefit, through the potential for creating a research experience with quality as well as teaching potential by visualizing the visual genetic inheritance of the pieces.

Keywords: repertoire; ideation; creativity. 


\section{Introdução}

A educação do design no brasil, assim como as correntes formativas, e ementas de cursos de graduação são temáticas discutidas há décadas pela academia, sendo trabalhos de Bomfim (1978), Witter (1984) e Niemeyer (1995) considerados marcos históricos da pesquisa em educação e design no Brasil. Segundo Freitas (1999), a herança advinda de escolas de design europeias justifica a estrita relação entre a atividade projetual e o ensino do design brasileiro. Considerado como a base da formação, a prática projetual segue sendo compreendida como umas das competências basais de um designer. Autores como Oliveira (2009), Norenberg e Franzato, (2012), Portas et al. (2012) e Martins e Wolff (2015) abordam a relação entre o ensino e a prática de projeto.

No entanto, com o passar dos anos, a clássica abordagem ao desenvolvimento de projetos assim como as competências exigidas dos designers vem sendo revistas e ampliadas diante de contextos culturais e sociais cada vez mais complexos (CELASCHI, 2007; ZURLO 2010; MOZOTTA, 2011). A atuação do designer, assim como a sua relação com a tecnologia vem provocando novas abordagens e interpretações, principalmente em relação ao processo de desenvolvimento de projetos, metodologia, inovação e inspiração.

Em Maldonado (2012), o processo de ideação do designer é amplamente discutido através de diferentes óticas e recortes. Uma das abordagens apresentadas pelo autor é a relação da criatividade com a área da psicologia cognitiva, através de processos de analogia, metáfora, abstração e associação de ideias. Ainda, o autor se refere à múltiplos instrumentos que reiteram a associação da prática de projeto com a capacidade cognitiva do designer e a criatividade. A ideação é interpretada como uma atividade metódica, inerente ao designer, e passível de estímulo, educação e inspiração (LUPTON, 2013).

\section{Pesquisa visual e associação de referências na fase de ideação}

Ao se avaliar a trajetória e evolução dos métodos de design através da literatura, é possível observar que a coleta, análise e ideação são componentes perenes na prática projetual (FREITAS; COUTINHO; WAECHTER, 2013). Autores de métodos consolidados, tanto no ensino, quanto na prática executiva do design, como Lobach (2001), Bonsiepe (1984), Burdek (1975), Munari (1981) e tantos outros, colaboram e evidenciam a necessidade de etapas voltadas à pesquisa e geração de alternativas. Enquanto as etapas de pesquisa e análise possam variar em termos de etapas, técnicas e profundidade, em decorrência da variedade de áreas em que se aplicam, o objetivo é notoriamente o mesmo: a coleta e construção de um repertório, e acervo referencial de informações e dados sobre o contexto, história, trajetória, necessidades, e problemas relacionados ao objeto em projetação. Já a fase de ideação, caracterizada pelos autores como geração de alternativas e/ou criatividade, envolvem nuances variadas na forma em que as informações coletadas e analisadas são aplicadas no processo de gerar soluções.

A visualização de pesquisas e sínteses visuais é um recurso poderoso no processo de projeto. Brown (2009) explica que um dos pilares do processo de design thinking é o uso das salas de projeto. Essas salas são recheadas com conceitos, protótipos, imagens, e uma série de outras referências que, através de sua disposição espacialmente próximas, permitem aos designers estabelecer conexões e chegar a insights relevantes ao projeto. Wheeler (2008) também refere-se à sala de guerra referindo-se ao mesmo propósito. 
Lupton (2013) apresenta o método de pesquisa visual como um meio de auxiliar no processo projetual a partir do seu desdobramento nas etapas de coleta, visualização e análise. $\mathrm{Na}$ etapa de coleta buscam-se referências visuais de acordo com critérios estabelecidos; na visualização, as imagens são postas lado a lado e buscam-se por padrões repetidos e tendências; na análise, registram-se as percepções a partir da visualização, podendo apontar sugestões para o desenvolvimento do projeto. A ferramenta apresentada pela autora demonstra-se versátil, podendo ser aplicada como um framework para auxiliar a compreender o problema (Figura 1A) ou como uma ferramenta de inspiração projetual (Figura 1B). No primeiro exemplo, a pesquisa visual explicita o superpovoamento de marcas nas faixas de cor vermelha e azul no espectro de cores e a consequente lacuna a ser explorada nas faixas verde e rosa. Nesse caso, as conclusões obtidas podem auxiliar os designers a formularem uma estratégia projetual mais adequada a partir da melhor compreensão do problema enfrentado. No segundo exemplo, a estratégia projetual já está definida e a pesquisa visual é utilizada para gerar um banco de referências visuais que alimenta diretamente a criação do pôster.

Figura 1 - Pesquisa visual como framework e como inspiração

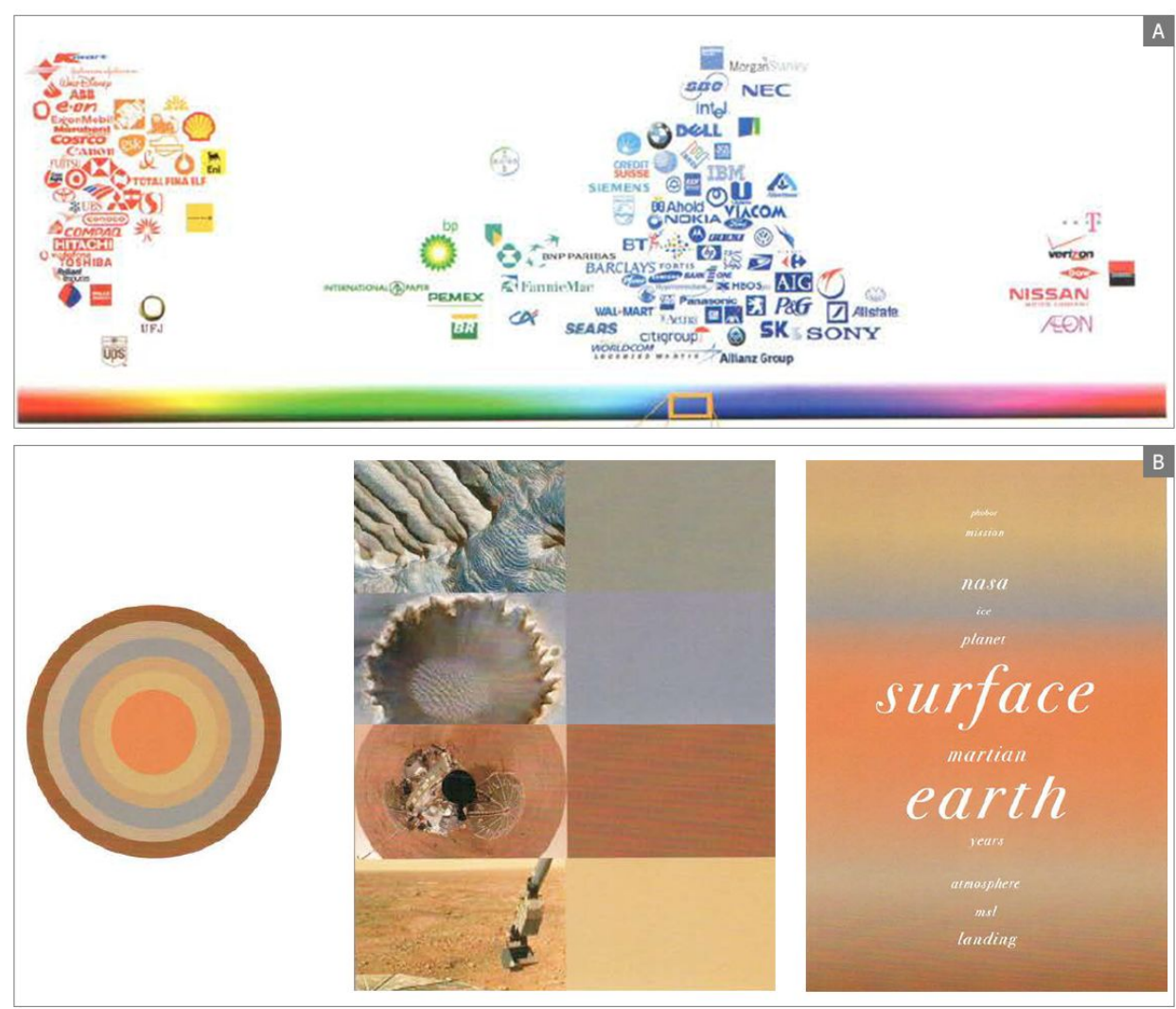

Fonte: adaptado de Lupton (2013)

Outros métodos de pesquisa com apoio na linguagem visual bastante utilizados na prática projetual são as análises descritas por Bonsiepe (1986). A análise sincrônica consiste em coletar dados relativos ao objeto de estudo comparado-o com outros objetos similares para se obter o um quadro geral do universo deste objeto. Esta análise visa obter requisitos projetuais e evitar a reinvenção de aspectos já utilizados. A análise diacrônica objetiva analisar a evolução do objeto ao 
longo do tempo com o intuito de demonstrar suas transformações históricas, assim como, obter um panorama geral de referência.

No livro Anatomy of Design de Steven Heller (2009), o autor realiza diversos exercícios de associação através da desconstrução de 49 peças de design gráfico com o intuito de apresentar as características multifacetadas de retroalimentação de referências e inspiração. 0 processo de desconstrução de cada uma destas peças; que variam entre posters, cartazes, capas de livro e propagandas; são baseadas na investigação da "herança genética" de cada um de seus elementos e recursos visuais que as compõem. A publicação é ilustrada através de múltiplos eixos temáticos em forma de linha do tempo que se estruturam de acordo com cada recurso empregado (Figura 2). Neles as peças são associadas de forma não-linear que utilizam recursos semelhantes, pois não existe nenhuma relação, exceto visual, entre elas.

Figura 2 - Desconstrução do livro Karim Rashid Evolution
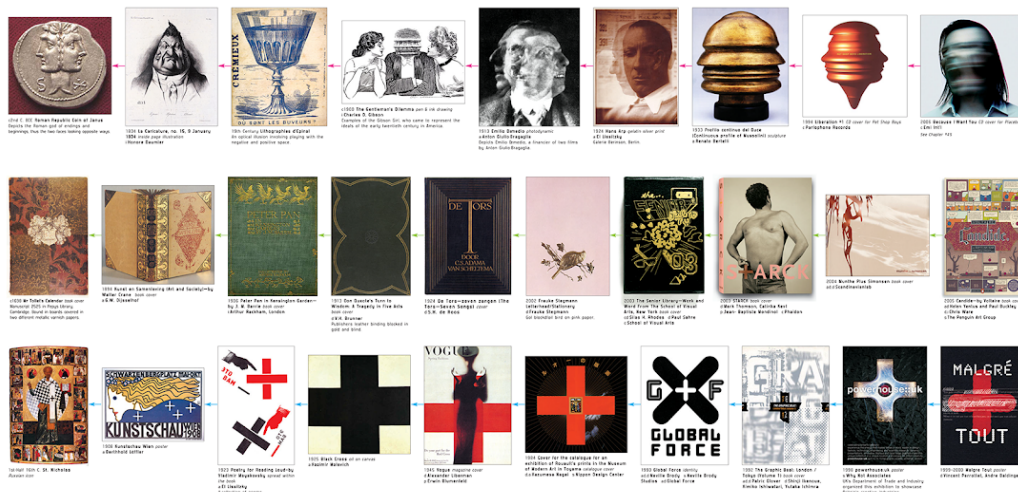

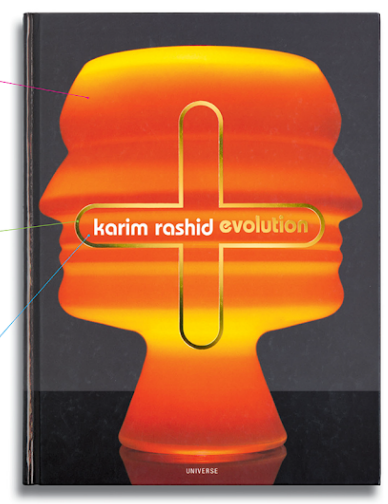

Fonte: Heller (2009)

Segundo Heller (2009), é impossível saber ao certo se as referências ou influências empregadas em projetos de design são propositais ou não, porém, é explícito o fato de que o design é cíclico e se alimenta de referências do passado. Considera-se a publicação é uma ferramenta importante para ilustrar a importância da associação no processo de design.

Para Buchanan (1985) o designer pode ser definido como um agente interlocutor dos indivíduos com o ambiente, sendo responsável pelo processo de interpretação e resolução de problemas. Zurlo (2004) defende um viés estratégico, caracterizando o designer como um agente criador de sentidos, tendo como principais competências: o ver, o prever e o fazer ver. Esta tríade de conceitos evidenciam a capacidade de interpretação da complexidade e desenvolvimento de projetos orientados em rumos e cenários estratégicos. Este conceito vem em direção ao que Flusser (2007) e Reyes (2010) apresentam a respeito da essência simulatória e visionária do designer cuja capacidade deve contemplar a previsão e representação de cenários futuros ainda inexistentes, e não formalizados a partir de processos e metodologias projetuais.

Cross (2011) evidencia que a solução de problemas, essência da atividade projetual, exige do designer competências e habilidades relacionadas inerentemente à capacidade de representação e repertório em diferentes níveis de abstração. Dentre tantas ferramentas o autor 
considera a utilização de recursos baseadas em gráficos, linguagens não-verbais, e modelagem visual como essenciais.

Zurlo (2004) define que uma das principais características da abordagem estratégica do design está no metaprojeto. Este conceito é complementado por Celaschi e Deserti (2007) ao ser definido como uma etapa orientada à "idealização e a programação do processo de pesquisa e projetação que se deseja usar". Já Moraes (2010a, 2010b), define o metaprojeto como um conjunto de ferramentas utilizadas no processo de investigação e desenvolvimento em projetos de design. Dentre as mais diversas ferramentas metaprojetuais existentes pode-se se citar os moodboards e construção de cenários.

A capacidade de estabelecer relações baseada em um repertório de referências e a sua associação entre elementos é uma das mais importantes competências de um designer, mas ao mesmo tempo uma das mais complexas e difíceis de serem ensinadas à estudantes de design. Observa-se que na prática docente é necessário conduzir os estudantes para uma prática metodológica e uma noção de que a ideação é um processo metódico e cíclico de construção, e não apenas baseado em um caminho linear de abstração e acaso. A geração de alternativas e ideias originais, cerne do processo criativo em metodologias de projeto, é diretamente relacionado à capacidade de estabelecer conexões, referências, linguagens e influências.

Tais características corroboram com as diretrizes curriculares nacionais dos cursos de graduação em Design, definido pelo Conselho Nacional de Educação/Câmara de Educação Superior em 2003. Dentre as diversas competências basais exigidas de um egresso de um curso superior de design constam: (I) capacidade criativa para propor soluções inovadoras, utilizando domínio de técnicas e de processo de criação; (II) capacidade para o domínio de linguagem própria expressando conceitos e soluções, em seus projetos, de acordo com as diversas técnicas de expressão e reprodução visual; (IV) visão sistêmica de projeto, manifestando capacidade de conceituá-lo a partir da combinação adequada de diversos componentes materiais e imateriais, processos de fabricação, aspectos econômicos, psicológicos e sociológicos do produto; (V) domínio das diferentes etapas do desenvolvimento de um projeto, a saber: definição de objetivos, técnicas de coleta e de tratamento de dados, geração e avaliação de alternativas, configuração de solução e comunicação de resultados; (VIII) visão histórica e prospectiva, centrada nos aspectos sócio-econômicos e culturais, revelando consciência das implicações econômicas, sociais, antropológicas, ambientais, estéticas e éticas de sua atividade.

\section{Ferramentas digitais e a pesquisa visual criativa}

Atualmente, inúmeras ferramentas digitais podem ser aplicadas para auxiliar o designer a executar procedimentos específicos nas diferentes fases do processo projetual. Dantas (2016) elenca ferramentas que podem ser utilizadas nas fases de inspiração, ideação e até mesmo em processos de apoio como a gestão do processo de design e a comunicação com o cliente. Uma das soluções tecnológicas recentes que mais impactaram na maneira como designers trabalham foi o advento do Google Images, que viabiliza uma pesquisa visual ampla em décimos de segundos. Cardoso (2010) compara uma pesquisa visual realizada atualmente com outra realizada nos anos 1990 que envolveria revistas, livros e outros artefatos físicos, a qual seria muito menos eficiente em termos de tempo e número de resultados encontrados.

A Figura 3 apresenta pesquisas visuais realizadas com as ferramentas digitais Google Images e Pinterest sobre o livro Evolution de Karim Rashid. As duas ferramentas apresentam uma 
grande quantidade de imagens relacionadas ao autor - como fotografias suas, produtos por ele projetados - e algumas imagens relacionadas ao seu livro - como a capa e páginas internas. A pesquisa realizada com o Google Images (Figura 3A) apresenta como recurso de refinamento da pesquisa botões contendo palavras-chave sobre o campo dos resultados. Este recurso que permite redirecionar ou focar ainda mais a pesquisa foi importado do Pinterest, que é reconhecido por auxiliar designers e usuários comuns a realizarem buscas relacionadas à inspiração e criatividade. Ambas as ferramentas utilizam o recurso de palavras-chave/tags de acordo com o grau de refinamento da pesquisa inicial - quanto mais específicos os termos da pesquisa, menos tags são sugeridas. Entretanto, o Google Images apresenta uma tolerância menor, normalmente apresentado mais sugestões que o seu concorrente.

Figura 3 - Pesquisa visual com ferramentas digitais

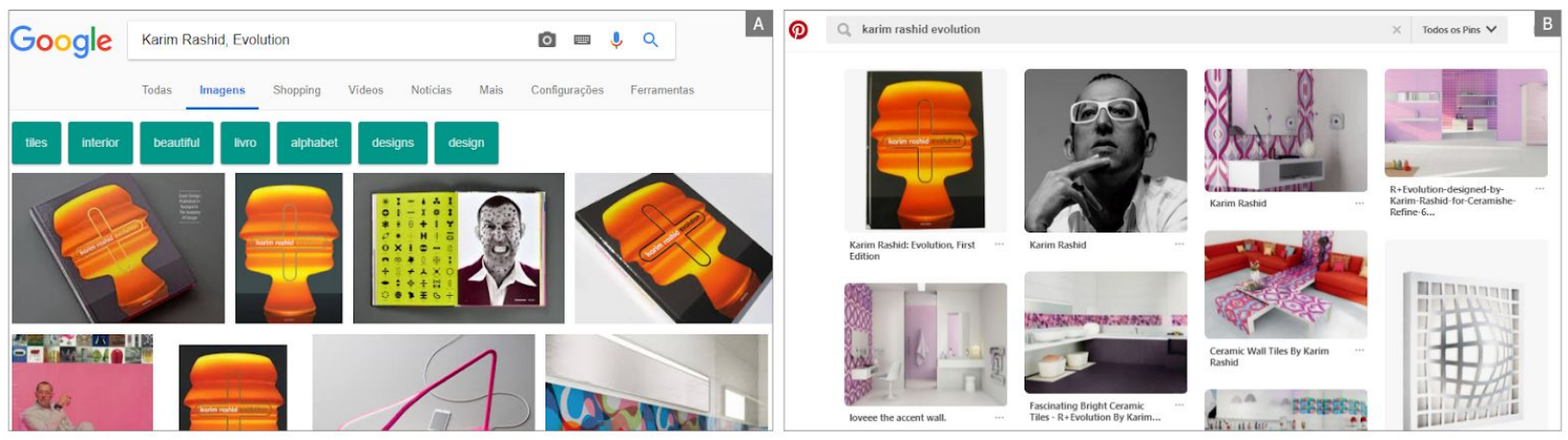

Fonte: os autores

Embora essas ferramentas mostrem-se eficientes e bastante práticas, nem sempre os resultados encontrados satisfazem as necessidades do designer - muitas vezes são apresentados resultados que não apresentam relação direta com o objeto de busca, a confiabilidade das fontes é questionável, a conexão entre os resultados exibidos é limitada e muitas vezes parece aleatória. O sistema de refinamento por tags auxilia a ampliar as possibilidades de pesquisa sobre um mesmo tema, porém não permite saltos em conteúdo que estimulariam a associação não-linear.

A Inspaedia, uma ferramenta idealizada por Maldonado (2013) que encontra-se em fase final de desenvolvimento, apresenta grande potencial em apoiar o designer em suas necessidades. A ferramenta utiliza como ideias construtivas as premissas de que o cérebro humano funciona de modo não-linear e que o sucesso em inovação e design está relacionado à qualidade das pesquisas realizadas. Embora não tenha sido feita exclusivamente para a pesquisa de imagens, como é o caso do Google Images e do Pinterest, ela baseia-se na linguagem visual para apresentar resultados de pesquisa. A Figura 4 demonstra a importância da linguagem visual na Inspaedia: no plano de frente, aparece o conteúdo específico de um dos resultados da pesquisa realizada, apresentado através de imagens e informações relevantes como ano, autor, descrição, links, tags e outros conteúdos relacionados; no plano de fundo aparecem imagens inseridas em círculos, sendo cada um dos círculos representante de um conteúdo específico. 
Figura 4 - Pesquisa visual com ferramentas digitais

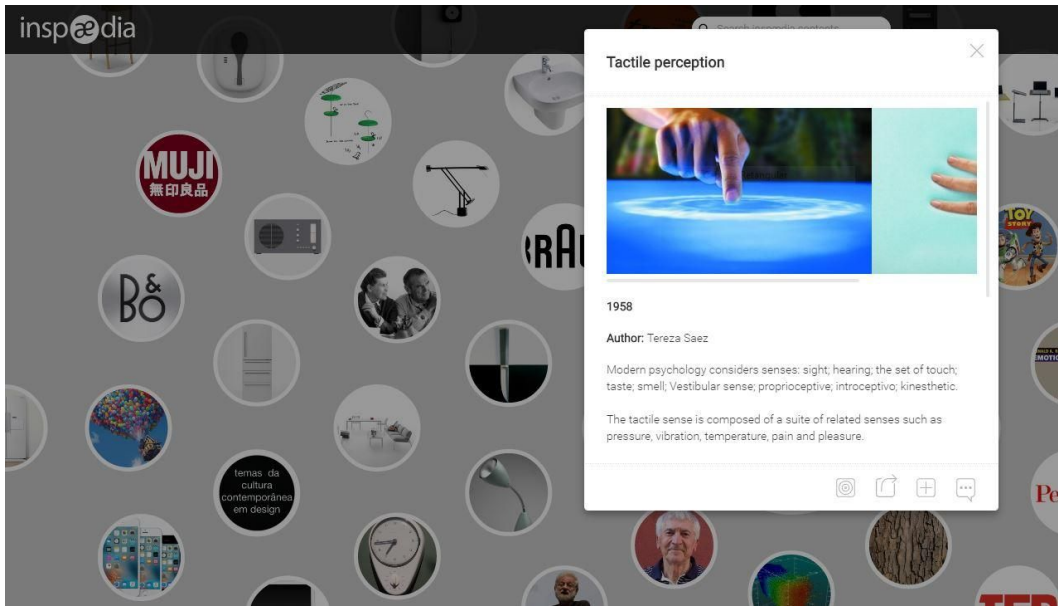

Fonte: os autores

Em relação à apresentação dos resultados da pesquisa, a Inspaedia utilizada a metáfora do mapa mental, em que um conteúdo principal está posicionado no centro (termo pesquisado), e conteúdos relacionados vão se afastando deste centro à medida em que seu grau de relacionamento diminui. A força das relações é determinada pela quantidade de tags compartilhadas entre os conteúdos - quanto mais tags em comum, mais fortemente relacionados estão os conteúdos e mais próximos na tela irão aparecer. O uso desta metáfora mostra-se adequado, pois segundo Lupton (2013) mapas mentais são diagramas associativos que permitem a exploração rápida de um determinado tópico. Esta interface estimula o usuário a navegar livremente entre os conteúdos mostrados, fornecendo pistas sobre o grau de relação dos conteúdos encontrados com o tópico principal. Dessa forma é possível navegar rápida e intuitivamente entre diferentes conteúdos relacionados.

A qualidade do conteúdo da Inspaedia é assegurada através de um sistema de curadoria, no qual uma base de dados em crescente expansão é alimentada por usuários especialistas, devidamente cadastrados na plataforma. Os especialistas criam os conteúdos e incluem as tags que determinarão os graus de relação do conteúdo criado com os demais conteúdos existentes no banco de dados da plataforma. Essa estratégia possibilita a apresentação de resultados confiáveis, relacionados através de conexões significativas, fatores que agregam valor à qualidade da pesquisa realizada pelos usuários.

Outras funcionalidades que merecem destaque na plataforma são: a possibilidade de centralizar um dos resultados periféricos de uma pesquisa realizada, o que reorganiza todo o mapa de resultados decorrente do novo conteúdo principal; a criação de coleções que organizam itens salvos segundo uma temática centralizadora (Figura 5); e a visualização histórica de conteúdos, exibidos em um diagrama de círculos sobre uma linha do tempo, o que funciona como um infográfico interativo que estabelece relações de proximidade por data em vez de compartilhamento de tags (Figura 6). 
MY COLLECTIONS

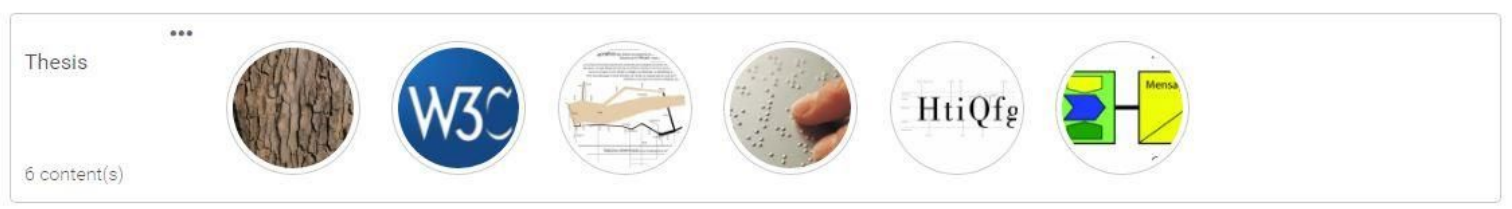

Fonte: os autores.

Figura 6 - Visualização histórica dos conteúdos.
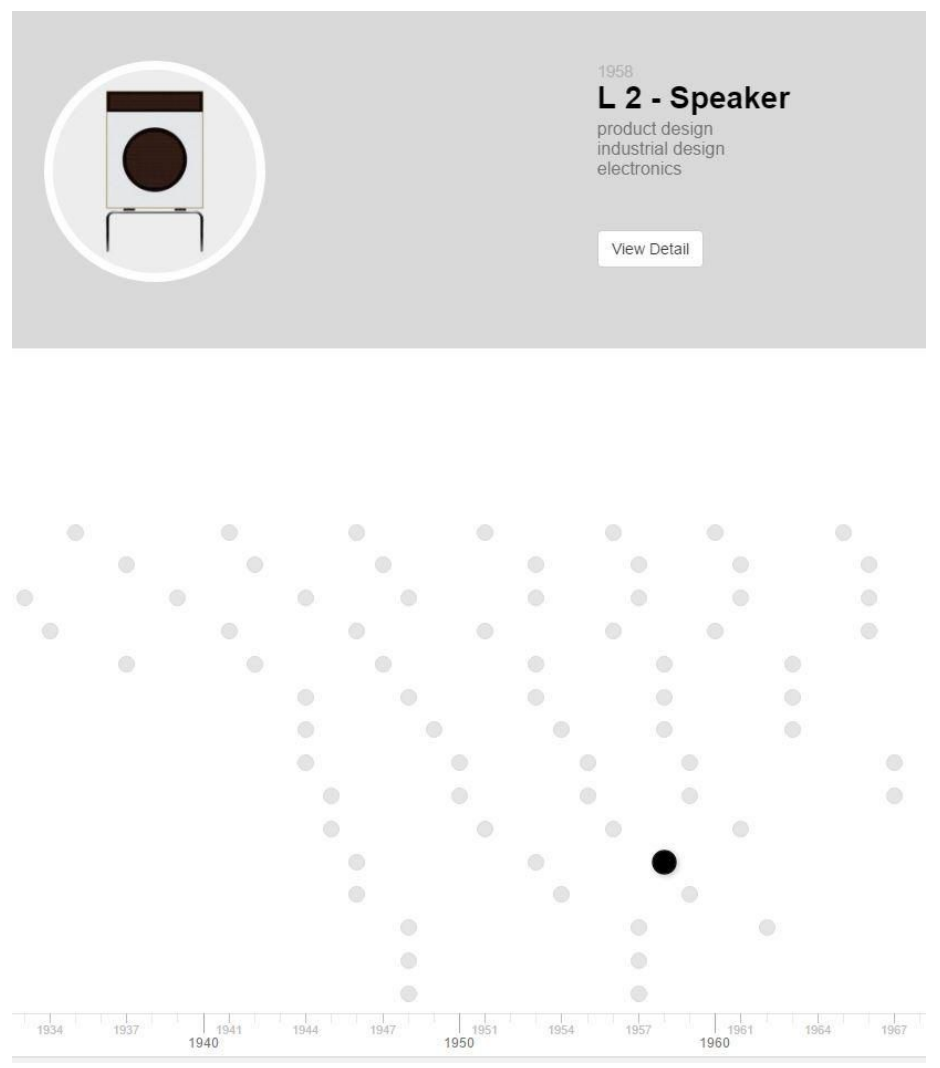

Fonte: os autores.

O recurso de criação de coleções abre possibilidades para a organização de pesquisas visuais de acordo com temáticas específicas. Isso permite a associação da Inspaedia com métodos de pesquisa em design. Nesse sentido, uma sugestão seria associar conteúdos de acordo com relações diacrônicas ou sincrônicas, tendo uma referência básica como ponto de partida, assim como sugere Bonsiepe (1986). Como exemplo, podem-se citar as imagens de páginas de livro impressas pela Kelmscott Press de William Morris (referência básica), que podem ser associadas com manuscritos medievais (referências diacrônicas) ou com trabalhos da Essex House Press, casa de impressão que teve forte influência de Morris em seus trabalhos (referência sincrônica) (Figura 7). 
Figura 7 - Referências diacrônica e sincrônica

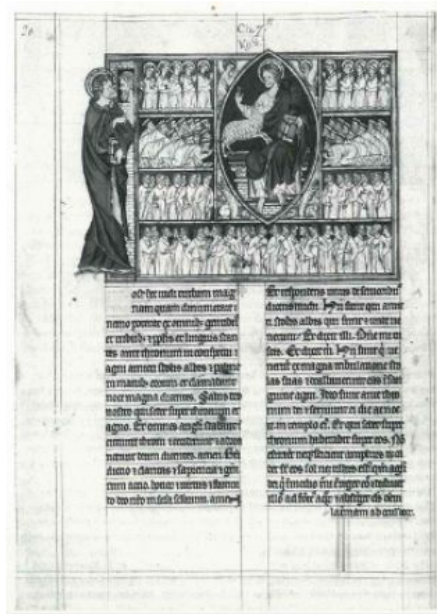

Referência diacrônica

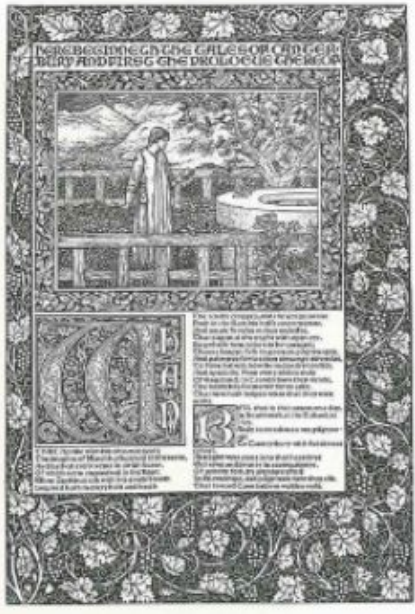

Referência básica

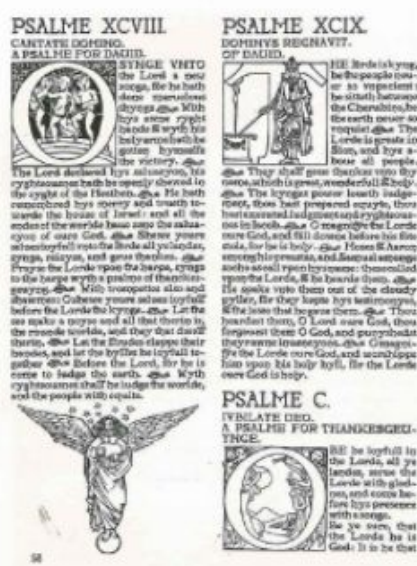

Referência sincrônica

Fonte: adaptado de Meggs (2009).

\section{Estudos de caso: aplicando a curadoria de conteúdo}

Com base no contexto explicitado neste trabalho, buscou-se estabelecer uma relação prática entre as características de associação não-linear oferecidos pela Inspaedia, com as competências centrais do processo de projetação do design gráfico. Acredita-se que através da mecânica e dinamismo da plataforma Inspaedia seja possível otimizar e tangibilizar a importância das referências, do processo de pesquisa, e da construção de repertório para a geração de novas ideias e a ideação como competência.

Para o estudo de caso proposto, utilizou-se de um dos exemplos apresentados por Heller (2009) para ser digitalizado e introduzido integralmente na plataforma Inspædia. O caso escolhido foi o pôster The Abuse You Yell at Your Kids Stays in the Family for Generations, desenvolvido por John Fisher na agência Saatchi \& Saatchi, Nova Zelândia. A desconstrução da peça está associada à 30 referências diferentes, categorizadas em três eixos distintos. Uma busca on-line foi realizada para cada um dos tópicos com o intuito de encontrar o máximo de informações sobre cada uma das peças. Enquanto algumas referências mostraram-se mais disponíveis na internet, outras foram baseadas nas informações do próprio livro. Todos os itens foram inseridos integralmente na plataforma Inspaedia com suas respectivas descrições, tendo as suas inter-relações estabelecidas pelo sistema a partir da associação entre temas relacionados. Para auxiliar no processo de ilustração foi desenvolvido um mindmap baseado no diagrama original de Heller (2009) (Figura 8).

As referências estão distribuídas em três eixos distintos baseados nos seus recursos visuais predominantes. O primeiro eixo diz respeito ao recurso de imagens sobrepostas, multiplicadas e escalonadas internamente, tendo como primeira menção a pintura Three Flags de Jasper Johns (1958). O segundo eixo de inspiração se refere a "bocas abertas", citando a capa de livro de 1921, Hurrah! Hurrah! Hurrah! como uma das precursoras no uso recurso. O terceiro eixo traça uma cronologia sobre o uso de "tipografia de ferragem", tendo o pôster de 1975, International Scientific Symposium: Fascism and Neofascism como base. 
Figura 8 - Mindmap baseado no diagrama original.

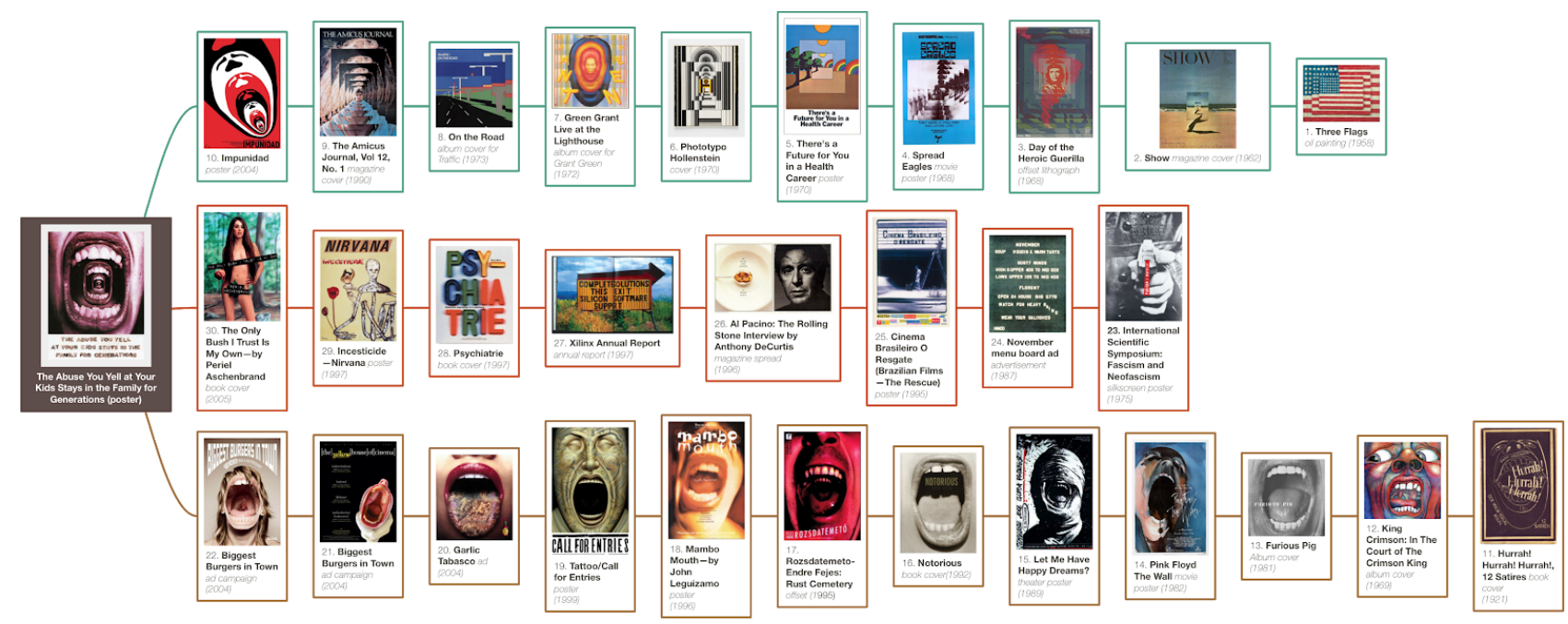

Fonte: o autor.

Após a alimentação da plataforma Inspaedia com todos os conteúdos relacionados entre si, observou-se que uma grande malha de relações entre os tópicos inseridos foi estabelecida, pois além das referências estarem ligadas à peça central, optou-se pela associação das referências entre cada um dos eixos (Figura 9). A interface da plataforma, ao contrário do livro, permite uma navegação interativa e não linear entre os conteúdos, o que promove uma experiência de descoberta significativamente mais rica - a funcionalidade de centralizar uma referência a partir do clique do mouse abre novas possibilidades de pesquisa a partir de cada clique.

A Figura 10 apresenta a referência principal deste estudo de caso como elemento central de uma pesquisa realizada na Inspaedia. Observa-se que os conteúdos inseridos na aplicação da herança genética estão mais próximos da referência central devido ao forte grau de relacionamento entre estes. Por outro lado, outros conteúdos que já faziam parte do banco de dados da plataforma também aparecem na tela principal, possibilitando novas conexões entre os conteúdos. 
Figura 9 - Mindmap baseado no diagrama original.

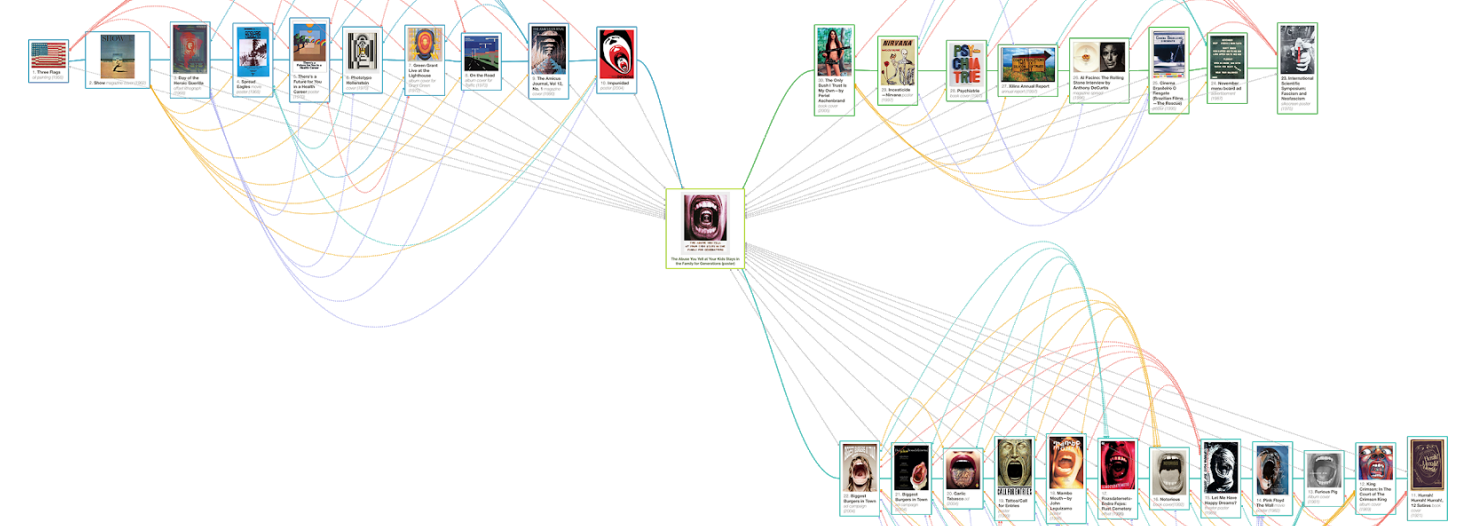

Fonte: o autor.

Figura 10 - Tela do Inspaedia

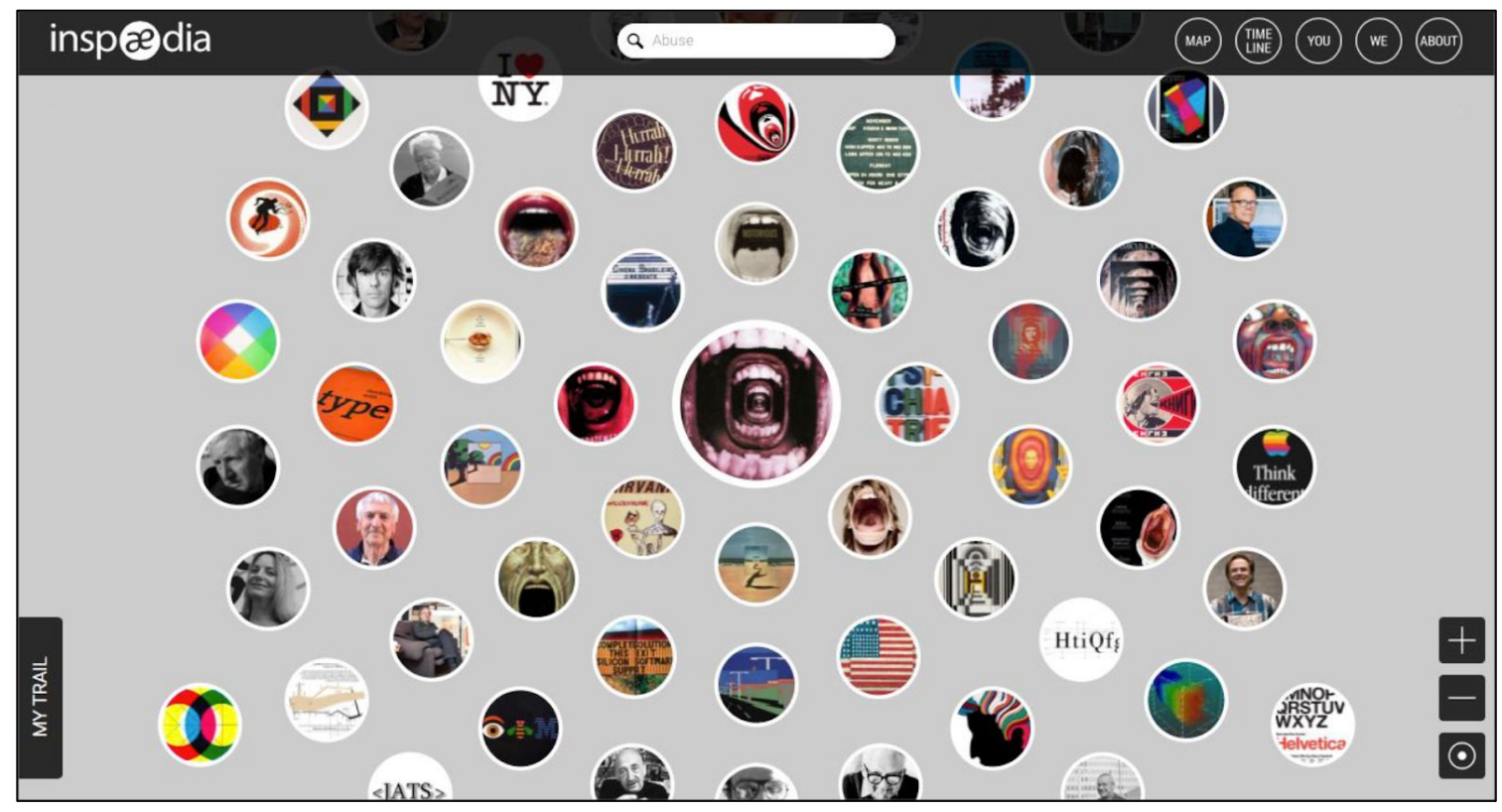

Fonte: o autor. 


\section{Considerações Finais}

A ascensão da tecnologia como um suporte à prática criativa deve ser encarada como uma oportunidade para a pesquisa e desenvolvimento de novas ferramentas. Nota-se que as ferramentas de pesquisa visual atualmente disponíveis possuem certas limitações que impõem restrições à qualidade de pesquisas realizadas. Nesse sentido, a Inspaedia apresenta-se como uma opção viável às ferramentas existentes, proporcionando pesquisas de qualidade através de uma interface intuitiva e flexível. A partir deste estudo, destacam-se como significativos os usos da plataforma como ferramenta de pesquisa para apoiar a criatividade em projetos, bem como, ferramenta de apoio ao ensino em design.

No primeiro caso, usuários que encontram-se em desenvolvimento de projetos podem realizar pesquisas confiáveis explorando as funcionalidades de navegação e criação de coleções. A exibição dos resultados na forma de mapa de imagens remonta, em um ambiente virtual, aquilo que Brown (2009) e Wheeler (2008) chamam de salas de projeto ou salas de guerra. Esse fator aliado às possibilidades interativas de navegação pelo conteúdo fomenta o estabelecimento de conexões e associação de conhecimentos, estimulando a capacidade criativa dos indivíduos. O uso das coleções estimula a memorização e associação de conteúdos de forma significativa, o que contribui para a construção de um repertório visual. Essas utilizações da Inspaedia estão alinhadas com a competências profissionais descritas em Brasil (2003), promovendo o seu desenvolvimento em designers profissionais ou em formação.

Outra questão de grande relevância é o uso da Inspaedia como ferramenta de ensino. Professores de design podem cadastrar-se como curadores de conteúdo e associar a plataforma com atividades de ensino. O estudo de caso aplicado neste trabalho é uma sugestão aplicável em sala de aula. A criação de coleções pode ser associada à métodos de pesquisa em design, como pesquisas diacrônicas ou sincrônicas. Atividades de avaliação também podem ser criadas a partir da análise de coleções criadas por alunos. Disciplinas com conteúdos históricos podem se beneficiar da curadoria e da aplicação da funcionalidade de visualização histórica disponível na ferramenta.

Considerando especificamente o estudo de caso realizado, observou-se que o dinamismo e mecânica propostos pela plataforma permitiria que designers, tanto profissionais como em formação, poderiam se beneficiar de um histórico a respeito da rota de inspiração de projetos de design. Ao serem expostos a uma cronologia, e associação não-linear sobre a utilização de determinados recursos, seria possível descobrir a essência e origem do seu uso. Além de proporcionar uma exposição crítica sobre o uso de elementos, a plataforma fomenta a ideia de que o design é cíclico e necessita de fontes variadas de inspiração como base para a plenitude da criatividade base da atividade projetual.

Apesar dos resultados terem sido relevantes, acredita-se que trabalhos futuros poderiam se beneficiar de experimentos fazendo uso da plataforma em cenários reais de projetação e das características colaborativas da plataforma. Desta forma poderiam ser verificadas a eficácia e impacto do uso de um suporte digital como a Inspaedia, e seus resultados em projetos de design em meio profissional e acadêmicos, principalmente em fase de ideação. 


\section{Referências}

BOMFIM, G. Desenho Industrial - Proposta para reformulação do Currículo Mínimo. Dissertação (Mestrado em Engenharia de Produção). Universidade Federal do Rio de Janeiro, Rio de Janeiro, 1978.

BONSIEPE, G.; KELLNER, P.; POESSNECKER, H. Metodologia experimental: desenho industrial. Brasília: CNPQ, 1984.

BRASIL. CNE/CES n. 0195/03, de 5 de agosto de 2003.

BROWN, T. Change by design. New York: HarperCollins, 2009.

BÜRDEK, B. Introdução à Metodologia do Design. In: História, teoria e prática do design de produtos. São Paulo: Edgard Blücher, 1975.

CELASCHI, F. Dentro al Progetto: Appunti di mercealogia Contemporânea. In: CELASCHI, F.; DESERTI, A. Design e innovacione: Strumenti e Pratiche per la Ricera Applicata. Carocci, Roma, 2007

CROSS, N. Design Thinking: Understanding how Designers think and work. New York: Berg, 2011. FREITAS, S. A influência de tradições acríticas no processo de estruturação do ensino/pesquisa de design. Tese (Doutorado em Engenharia de Produção). Universidade Federal do Rio de Janeiro, Rio de Janeiro, 1999.

FREITAS, F.; COUTINHO, S.; WAECHTER, H. Análise de Metodologias em Design: a informação tratada por diferentes olhares. Estudos em Design, n. 21, v. 1, 2013.

HELLER, S. Anatomy of Design: Uncovering the Influences and Inspiration in Modern Graphic Design. Masschussets: Rockport Publishers, 2009.

LÖBACH, B. Design Industrial: Bases para configuração dos produtos industriais. Rio de Janeiro: Edgard Blücher, 2001

LUPTON, Ellen. Intuição, ação, criação. São Paulo: Gustavo Gili, 2013.

MALDONADO, P. Inovação, design et cetera. Tese (Doutorado em Design). Lisboa: Faculdade de Arquitectura da Universidade Técnica de Lisboa, 2012.

MALDONADO, P. Inspaedia: Inteligência inspiradora criativa. In:

(http://www.experimentadesign.pt/2013/pt/01-02-00-inspaedia.html), 2013.

MARTINS, V.; WOLFF, F. Competências em disciplinas de Projeto de Produto. Estudos em Design, Vol. 23, No. 2, p. 37-58, 2015.

MOZOTA, B. Gestão do Design. Porto Alegre: Bookman, 2011.

MUNARI, Bruno. Das coisas nascem coisas. São Paulo: Martins Fontes, 1981.

NIEMEYER, L. Desenvolvimento e Modernismo: implicações para o ensino de Design na ESDI. 1995. Dissertação (Mestrado em Educação). Universidade Federal Fluminense, Niterói, 1995.

NORENBERG, G. Cultura de projeto para integrar universidade e empresa: uma experiência aplicada. In: Congresso Brasileiro de Pesquisa e Desenvolvimento em Design, 10, São Luís, 2012.

OLIVEIRA, I. 0 ensino de projeto na graduação em Design no Brasil: o discurso da prática pedagógica. Tese (Doutorado em Design). Pontifícia Universidade Católica do Rio de Janeiro, Rio 
de Janeiro, 2009.

PORTAS, R. et. Al. Disciplina de projeto DSG1002 - Planejamento: uma proposta pedagógica inovadora. In: Congresso Brasileiro de Pesquisa e Desenvolvimento em Design, 10, São Luís, 2012. WITTER, G. Desenho Industrial - Uma perspectiva Educacional. São Paulo: CNPq / Coordenação Editorial, 1985.

WHEELER, A. Design de identidade da marca. Porto Alegre: Bookman, 2008

ZURLO, F. Design Strategico. In: Spazi e le Arti, vol. IV, n. XXI. GLI, S. Roma: Enciclopedia Treccani, 2010. 